\title{
1 Unraveling the antiviral activity of plitidepsin by subcellular and
}

\section{2 morphological analysis}

5 AUTHORS: Martin Sachse ${ }^{1}$, Raquel Tenorio ${ }^{1 \uparrow}$, Isabel Fernández de Castro ${ }^{1 \pi}$, Jordana 6 Muñoz-Basagoiti ${ }^{2, *}$, Daniel Perez-Zsolt ${ }^{2, *}$, Dàlia Raïch-Regué2,*, Jordi Rodon ${ }^{3, *}$, Alejandro 7 Losada $^{8}$, Pablo Avilés ${ }^{8}$, Carmen Cuevas ${ }^{8}$, Roger Paredes ${ }^{2}$, Joaquim Segalés ${ }^{4,5}$, Bonaventura 8 Clotet $^{2,6,7}$, Júlia Vergara-Alert ${ }^{3}$, Nuria Izquierdo-Useros ${ }^{2,6, \&}$, Cristina Risco $^{1, \&}$

\section{0 ॠ Equal contribution}

11

\section{*Equal contribution}

\&Corresponding authors: NI-U nizquierdo@irsicaixa.es ; CR crisco@cnb.csic.es

\section{Affiliations:}

$17{ }^{1}$ Centro Nacional de Biotecnología, CSIC, 28049 Madrid, Spain

18 IrsiCaixa AIDS Research Institute, 08916, Badalona, Spain

$19{ }^{3}$ IRTA, Centre de Recerca en Sanitat Animal (CReSA, IRTA-UAB), Campus de la UAB, 08193

20 Bellaterra (Cerdanyola del Vallès), Spain

$21{ }^{4}$ UAB, CReSA (IRTA-UAB), Campus de la UAB, 08193 Bellaterra (Cerdanyola del Vallès), 22 Spain

23 Departament de Sanitat i Anatomia Animals, Facultat de Veterinària, UAB, 08193 Bellaterra 24 (Cerdanyola del Vallès), Spain

$25{ }^{6}$ Germans Trias i Pujol Research Institute (IGTP), Can Ruti Campus, 08916, Badalona, Spain

$26{ }^{7}$ University of Vic-Central University of Catalonia (UVic-UCC), 08500 Vic, Spain

$27{ }^{8}$ PharmaMar S.A., 28770 (Colmenar Viejo), Madrid Spain 


\section{ABSTRACT}

33 The pandemic caused by the new coronavirus SARS-CoV-2 has made evident the need for broad-

34 spectrum, efficient antiviral treatments to combat emerging and re-emerging viruses. Plitidepsin 35 is an antitumor agent of marine origin that has also shown a potent pre-clinical efficacy against 36 SARS-CoV-2. Plitidepsin targets the host protein eEF1A (eukaryotic translation factor 1 alpha 1) 37 and affects viral infection at an early, post-entry step. Because electron microscopy is a valuable 38 tool to study virus-cell interactions and the mechanism of action of antiviral drugs, in this work 39 we have used transmission electron microscopy (TEM) to evaluate the effects of plitidepsin in 40 SARS-CoV-2 infection in cultured Vero E6 cells 24 and $48 \mathrm{~h}$ post-infection. In the absence of 41 plitidepsin, TEM morphological analysis showed double-membrane vesicles (DMVs), organelles

42 that support coronavirus genome replication, single-membrane vesicles with viral particles, large 43 vacuoles with groups of viruses and numerous extracellular virions attached to the plasma 44 membrane. When treated with plitidepsin, no viral structures were found in SARS-CoV-2-infected 45 Vero E6 cells. Immunogold detection of SARS-CoV-2 nucleocapsid (N) protein and double46 stranded RNA (dsRNA) provided clear signals in cells infected in the absence of plitidepsin, but 47 complete absence in cells infected and treated with plitidepsin. The present study shows that 48 plitidepsin completely blocks the biogenesis of viral replication organelles and the morphogenesis 49 of virus progeny. Electron microscopy morphological analysis coupled to immunogold labeling of 50 SARS-CoV-2 products offers a unique approach to understand how antivirals such as plitidepsin 51 work. 
Infection caused by the severe acute respiratory syndrome coronavirus 2 (SARS-CoV-2) urgently

63 needs effective antiviral treatments with a significant clinical benefit for hospitalized patients. So

64 far, randomized clinical trials have failed to identify potent antivirals targeting the virus, with the

65 only exception of remdesivir and molnupiravir, which have recently shown clinical benefits when

66 administered early upon infection (Beigel et al., 2020; Garibaldi et al., 2021; Grein et al., 2020;

67 Imran et al., 2021). As it happens with all viruses, coronaviruses have a reduced number of

68 molecular druggable targets, and as new variants arise, these targets evolve and could eventually

69 develop antiviral resistance. An interesting approach to overcome these limitations relies on the

70 use of compounds against highly conserved cellular host factors required to complete the

71 replication cycle of distinct types of viruses, which offer a common targeted solution to diverse

72 viral threats. Furthermore, targeting host factors could offer a pan-antiviral strategy to combat not

73 only viruses known at present, but also future pandemics to come (Baggen et al., 2021).

74 Presently, there are only a limited number of approved drugs involved in targeting host factors at

75 post-entry steps (Baggen et al., 2021). This approach is especially relevant for pan-antiviral

76 solutions given that viruses may use alternative pathways to enter a cell, but will most likely

77 converge at intracellular processes involving genome replication and protein production. One of

78 these compounds is plitidiepsin, which has shown a potent preclinical efficacy against SARS-

79 CoV-2 by targeting the host protein eEF1A (Losada et al., 2016; Rodon et al., 2021; White et al.,

80 2021). In 2018, the Therapeutic Goods Administration (TGA; Australian Government) approved

81 the combination of plitidepsin with dexamethasone for the treatment of patients with

82 relapsed/refractory multiple myeloma (https://www.tga.gov.au/auspar-plitidepsin). Currently,

83 plitidepsin is being evaluated in a phase 3 , multicenter, randomized, controlled trial to determine

84 the efficacy and safety of two dose levels of plitidepsin versus control in adult patient requiring

85 hospitalization for management of moderate Coronavirus infectious disease 2019 (COVID-19)

86 (ClinicalTrials.gov Identifier: NCT04784559). eEF1A2 is necessary to transport aminoacyl-

87 tRNAs to the A site of the ribosome during protein translation, but is also implicated in other

88 activities (Mateyak and Kinzy, 2010) such as inhibition of apoptosis (Sun et al., 2014), proteasome

89 degradation (Hotokezaka et al., 2002), and actin bundling and cytoskeleton reorganization

90 (Edmonds et al., 1998) among other non-canonical functions. Also, eEF1A2 is implicated in the

91 replication of distinct viruses, including coronaviruses (Zhang et al., 2014), and was identified as 
92 a potential SARS-CoV-2 interacting protein in one of the first screenings performed to identify

93 novel targets (Gordon et al., 2020).

94

95 Upon SARS-CoV-2 infection, plitidepsin inhibits nucleocapsid viral protein expression and viral 96 induced cytopathic effect in vitro (Rodon et al., 2021; White et al., 2021). In addition, it also 97 reduces genomic and subgenomic RNA expression (White et al., 2021). Current models of SARS98 CoV-2 replication propose that upon viral fusion, non-structural viral proteins form a replication99 transcription complex that is continuous with the ER and has a double membrane vesicle (DMV) 100 morphology that shelters the viral genome replication (Baggen et al., 2021; Wolff et al., 2020a).

101 A negative RNA strand is used as a template for the generation of positive strands that are 102 translated and incorporated into nascent viruses (Baggen et al., 2021; Wolff et al., 2020a). 103 Discontinued transcription of positive RNA strands produce negative subgenomic RNAs, which 104 are then used as templates for positive subgenomic RNA generation that codify for structural and 105 accessory proteins (Baggen et al., 2021; Wolff et al., 2020a). Translation of viral proteins is 106 facilitated by mRNA export via molecular pores located in the DMV that enable viral protein 107 production in the cytoplasm (Wolff et al., 2020b). Yet, how plitidepsin exerts its intracellular 108 antiviral activity and influences the formation of viral replication DMV remains unknown.

110 Here we aimed to explore the antiviral effect of plitidepsin at the cellular level to understand its 111 impact on SARS-CoV-2 replication and DMV formation. Using transmission electron microscopy 112 (TEM), we recapitulated the infectious SARS-CoV-2 cycle in Vero E6 cells and observed a lack 113 of viral DMVs in plitidepsin-treated cells. Complementary immunohistochemistry analyses using 114 nucleocapsid and dsRNA immunogold labeling unambiguously confirmed the lack of viral 115 replication in plitidepsin treated cells. 


\section{MATERIAL \& METHODS}

120 Biosafety Approval. The biologic biosafety committee of the Research Institute Germans Trias i

121 Pujol approved the execution of SARS-CoV-2 experiments at the BSL3 laboratory of the Center

122 for Bioimaging and Comparative Medicine, CMCiB (CSB-20-015-M3).

Materials. Plitidepsin was synthesized at PharmaMar, S.A. (Colmenar Viejo, Madrid, Spain).

126 Cell culture, viral isolation and titration. Vero E6 cells (ATCC CRL-1586) were cultured in Dulbecco's modified Eagle medium (Invitrogen) supplemented with 10\% fetal bovine serum (FBS; Invitrogen), $100 \mathrm{U} / \mathrm{mL}$ penicillin, $100 \mu \mathrm{g} / \mathrm{mL}$ streptomycin (all from Invitrogen). SARSCoV-2 D614G was isolated from a nasopharyngeal swab collected in March 2020 in Spain in Vero E6 cells as previously described in detail (Rodon et al., 2021). The virus was propagated for two

134 in 10-fold serial dilutions on Vero E6 cells to calculate the TCID 50 per mL.

136 Cellular infection. Vero E6 cells were infected with SARS-CoV-2 at a multiplicity of infection 137 (MOI) of 0.02 plaque forming units (PFU) per cell for 24 and 48 hours (h) in the presence or 138 absence of 0.2 and $0.05 \mu \mathrm{M}$ of plitidepsin added at the time of infection. These two concentrations 139 are close to the $\mathrm{IC}_{90}$ and $\mathrm{IC}_{50}$ of plitidepsin, respectively, determined by the SARS-CoV-2 induced

140 cytopathic effect on Vero E6 cells (Rodon et al., 2021). As negative controls, Vero E6 cells were 141 treated with or without plitidepsin for the same time but without virus. At each studied time point, 142 cell monolayers were chemically fixed using two different protocols depending on the type of 143 analysis (morphology or immunohistochemistry).

145 Morphology Analysis. Cell monolayers were fixed with 4\% paraformaldehyde and 1\% 146 glutaraldehyde in phosphate buffered saline (PBS) for $2 \mathrm{~h}$ at room temperature (RT). Cells were 147 removed from the plates in the fixative, pelleted by centrifugation and washed three times with 
148 PBS. Post-fixation of cell pellets was done on ice with $1 \%$ osmiumtetroxide $+0.8 \%$ potassium

149 ferrocyanide in water. Afterwards the pellets were dehydrated on ice with increasing 150 concentrations of acetone and processed for embedding in the epoxy resin EML-812 (Taab

151 Laboratories), as previously described (Tenorio et al., 2018). Sections of cells in epoxy resins have

152 high contrast and optimal morphological details. Infiltration with epoxy resin was performed at

153 RT. All samples were polymerized at $60^{\circ} \mathrm{C}$ for $48 \mathrm{~h}$. Ultrathin sections $(50-70 \mathrm{~nm})$ were cut with a

154 Leica UC6 microtome and placed on uncoated 300 mesh copper grids. Sections were contrasted

155 with 4\% uranyl acetate and Reynold's lead citrate. Images were taken with a Tecnai G2 TEM

156 operated at $120 \mathrm{kV}$ with a Ceta camera or with a Jeol 1400 operated at $120 \mathrm{kV}$ with a Gatan Rio

157 camera. At least 50 cells per condition were studied by TEM.

159 Immunohistochemistry. Cells were fixed with 4\% paraformaldehyde and $0.1 \%$ glutaraldehyde in PBS for $1 \mathrm{~h}$ at RT and removed from the plates in the fixative, pelleted by centrifugation and washed three times with PBS. Cell pellets were incubated 30 min with $2 \%$ uranyl acetate in water

162 at RT, gradually dehydrated on ice with ethanol and infiltrated at RT with LR-White acrylic resin 163 as previously described (de Castro Martin et al., 2017). Sections of cells in acrylic resins have low 164 contrast but an optimal preservation of protein epitopes, which is fundamental for immunolabeling 165 studies. After polymerization at 60 degrees for $48 \mathrm{~h}$, the samples were sectioned using a Leica UC6 166 ultramicrotome. Ultrathin sections were collected on copper grids with a carbon-coated Formvar 167 film. For immunogold labeling, unspecific binding on sections was blocked by incubation with 168 Tris-buffered gelatin (TBG) for 5 minutes. N protein was labeled with the rabbit anti-SARS-CoV1692 nucleocapsid antibody (GXT 135357 GeneTex) diluted 1/50 in TBG for 1h. Double stranded 170 RNA (dsRNA), an intermediate of viral replication, was labeled with the mouse monoclonal anti171 dsRNA J2 antibody (10010200, English and Scientific Consulting Kft, SCICONS) diluted 1/30 in

172 TBG for 1h. After three washes with PBS and incubation with TBG for 5 minutes, grids were 173 labeled with a secondary antibody, corresponding to the species of the first antibody, conjugated 174 with 10-nm colloidal gold particles (BB international) in TBG for $30 \mathrm{~min}$. Sections were washed 175 three times with PBS and five times with milliQ water and stained with saturated uranyl acetate 176 for $20 \mathrm{~min}$. After washing three times with milliQ water, grids were allowed to dry at RT. Images 177 were taken with a Jeol 1400 TEM operated at $80 \mathrm{kV}$ with a Gatan One view camera or with a Jeol 
1781011 TEM operated at $100 \mathrm{kV}$ with a Gatan ES1000W camera. At least 50 cells per condition 179 were studied by TEM.

\section{RESULTS}

184 To understand how plitidepsin exerts its mechanism of action, we first followed SARS-CoV-2

185 replication cycle using electron microscopy. We found no replication organelles nor viral particles 186 in cells infected for $24 \mathrm{~h}$ at an MOI of 0.02 , although compared to control cells, the viral infection

187 induced some stress in cells, which showed mitochondria with swollen cristae and Golgi with 188 swollen cisternae (not shown).

189 In Vero E6 cells infected for $48 \mathrm{~h}$ at an MOI of 0.02 , clusters of characteristic DMVs, which are 190 the replication organelles of SARS-CoV-2 (Ogando et al., 2020), were present in the cytoplasm

191 and occupied a significant area of the cytosol (Figure 1A and B). DMVs often had an electron 192 lucent content with fibrillar material (Figure 1B). Intracellular viral particles and extracellular 193 virions attached to the plasma membrane were abundant (Figure 1A and C). On average, in 194 ultrathin sections of infected cells we found 30 intracellular viral particles and 73 extracellular 195 particles attached to the plasma membrane per cell. Single or very few viral particles were present 196 inside small vesicles with an electron lucent lumen while larger vacuoles with numerous viral 197 particles were often observed (Figure 1C). These vacuoles that contained internal membranes 198 and/or amorphous electron dense material might represent late endosomes/lysosomes. We seldom 199 observed budding of viral particles into the endoplasmic reticulum (ER) (Figure 1C).

200 When $0.2 \mu \mathrm{M}$ of plitidepsin was added to Vero E6 cells, the drug had a profound impact on viral 201 replication 48h later (Figure 1D-F). We did not observe any DMVs in the cytoplasm, nor viral 202 particles inside cells or at the plasma membrane (Figure 1D). We found clusters of potential single 203 membrane vesicles present in the cytoplasm, which are formed in early stages of SARS-CoV-2 204 infection (Eymieux et al., 2021a), that could however also reflect parts or a swollen Golgi (Figure 205 1E). Lipid droplets (LDs) and glycogen granules were abundant (Figure 1F), something also 206 observed in mock-infected cells treated with $0.2 \mu \mathrm{M}$ of plitidepsin (Figure S1). This effect was 
207 observed in cells incubated with a lower concentration of plitidepsin, that is $0.05 \mu \mathrm{M}$, only less 208 pronounced (Figure S2).

209 We then studied in detail the effects of 0.05 or $0.2 \mu \mathrm{M}$ of plitidepsin on the assembly of SARS210 CoV-2 replication organelles or DMVs. Of note, these two concentrations are close to the $\mathrm{IC}_{50}$ and 211 IC90 estimated for SARS-CoV-2 induced cytopathic effect on Vero E6 cells (Rodon et al., 2021). 212 When plitidepsin was added to Vero E6 cells at the same time of viral infection (MOI of 0.02 for $21348 \mathrm{~h}$ ), both concentrations had a deep impact on the biogenesis of DMVs (Figure 2). Cells infected 214 without plitidepsin contained numerous, typical DMVs with fibrillar content surrounded by viral 215 particles inside single-membrane vesicles (Figure 2A-C) but when the drug was added no DMVs 216 were found (Figure 2D-I). Already at the low concentration, no DMVs were found in the cytosol 217 (Figure 2D-F). Single membrane vesicles were present but they did not contain fibrillar content 218 in their lumen as opposed to infected cells, and this could reflect a part of a swollen Golgi or ER (Figure 2F and I). These morphological analyses on plitidepsin-treated cells failed to identify any structures implicated in SARS-CoV-2 replication that were unambiguously detected in untreated infected cells (Figures 1A-C and 2A-C).

The absence of structures implied in viral replication was confirmed by immunodetection of two

223 key products of SARS-CoV-2: the nucleocapsid and double stranded RNA (dsRNA). The 224 nucleocapsid participates in replication and translation of viral RNA and maintains the structure 225 of ribonucleoprotein complex, whereas the dsRNA is synthesized by the viral polymerase in the 226 host cell, once viral replication has started in DMVs. For both targets, no signal by immunogold 227 labeling was detected in non-infected cells, either non treated with plitidepsin or incubated with 228 low or high concentration of plitidepsin (Figure S3 and S4). However, virus-infected cells showed a strong labeling for the nucleocapsid in the cytosol and in viral particles that accumulated intraas well as extracellularly (Figure 3A-C). Coherent with the morphological observations, after application of plitidepsin at $0.05 \mu \mathrm{M}$, no signal was detected by antibody labelling for nucleocapsid (Figure 3D-F). The absence of labelling was also found for the high concentration of plitidepsin $(0.2 \mu \mathrm{M})$ (Figure 3G-I). In SARS-CoV-2 infected cells without plitidepsin, the labeling for dsRNA was restricted to the lumen of large electron lucent vesicles, which represent the DMVs (Figure 4A-C). Due to the low contrast of ultrathin sections of cells embedded in the LR-White acrylic resin, the fibrillar content in the lumen of DMVs is not visible in these samples but the labeling of dsRNA marked them unequivocally as DMVs. After application of Plitidepsin at 0.05 
or $0.2 \mu \mathrm{M}$, no signal for dsRNA was detected by immunogold labelling (Figure 4D-I). Overall,

239 immunodetection of viral proteins and genetic material confirmed that the morphological analysis

240 performed corresponded to viral replication structures and that plitidepsin completely blocked the

241 assembly of the viral replication organelles or DMVs and the accumulation or viral nucleocapsid

242 protein and dsRNA. Taken together these results provide evidence that plitidepsin inhibits

243 intracellular viral replication and abrogates the formation of DMVs.

\section{DISCUSSION}

248 The TEM analysis of SARS-CoV-2-infected Vero E6 cells performed herein reveals the formation 249 of DMV structures characteristic of the viral replication organelle, and the accumulation of 250 intracellular viral particles in small vesicles and large vacuoles as well as extracellular virions at the plasma membrane. These structures have been described before as characteristic features of SARS-CoV-2 infection in cell culture (Eymieux et al., 2021a, 2021b; Ogando et al., 2020). In this study, infected cells displayed a clear specific labelling for both the nucleocapsid viral protein and the dsRNA viral replication intermediate. Specific labelling of two key viral products is highly relevant in a context in which TEM analysis of SARS-CoV-2-infected samples has led to the misidentification of viral particles and to ambiguous results (Dittmayer et al., 2020; Miller and Goldsmith, 2020). Together, the morphological analysis along with the immunogold detection of two complementary SARS-CoV-2 products performed herein provided conclusive evidence that the subcellular structures detected in infected cells represented viral replication organelles and virus progeny. In the present set of experiments, plitidepsin abrogated the formation of DMVs and

261 the detection of nucleocapsid and dsRNA viral products in SARS-CoV-2-infected Vero E6 cells. 262 Since plitidepsin interferes with the host factor eEF1A implicated in RNA translation (Losada et 263 al., 2016), it is worthwhile to know the impact of this mechanism on the formation of DMVs.

265 The antiviral effect of plitidepsin against SARS-CoV-2 is mediated throughout inhibition of the 266 host protein eEF1A. siRNA silencing of eEFA1A in host cells induces a significant reduction in the nucleocapsid protein levels, as well as a reduction in the viral RNA, which demonstrates a 
268 direct involvement of eEF1A in the viral replication (Zhang et al., 2014). In addition, the exposure 269 of plitidepsin to cells at the moment of SARS-CoV-2 infection reduced the viral replication and 270 transcription, which induced a reduction in the accumulation of genomic RNA and sub-genomic 271 N RNA viral levels, respectively (White et al., 2021). Due to the known high sensitivity of 272 coronavirus to translation inhibitors (Bojkova et al., 2020; van den Worm et al., 2011), especially 273 at an early stage of infection, a plitidepsin-mediated inhibition of SARS-CoV-2 protein translation 274 process could represent one possible mechanism, which could lead to the abrogation of DMV 275 formation. The results gathered from the present experiments demonstrate that a concentration as 276 low as $50 \mathrm{nM}$ of plitidepsin, completely abolished the formation of DMVs, and the synthesis of $\mathrm{N}$ 277 protein and viral dsRNA in SARS-CoV-2 infected Vero E6 cells both at 24 and 48 h post278 inoculation. The plitidepsin-mediated anti-SARS-CoV-2 activity at such a low concentration may 279 be the result of a highly specific inhibition of genomic RNA viral translation. This specific antiviral 280 effect is explained by the lack of plitidepsin-mediated protein synthesis inhibition in eukaryotic 281 cells at high concentrations (e.g., $450 \mathrm{nM}$ or higher), far above those used herein (Losada et al., 282 2016). Inhibition of the viral protein translation may affect several essential proteins, such as non283 structural proteins, whose predicted transmembrane domains are key for DMV formation during 284 the replication of distinct coronaviruses (Angelini et al., 2013; Oudshoorn et al., 2017; Wolff et 285 al., 2020a). It is tempting to speculate that the lack of translation of these viral proteins could 286 directly abrogate the formation of these replication-transcription complexes necessary for DMV 287 formation. This possible mechanism is supported by prior observations where plitidepsin treatment 288 decreased nucleocapsid content and reduced subgenomic RNA detection (Rodon et al., 2021; 289 White et al., 2021). An alternative mechanism has been recently proposed with eEF1A binding to 290 membranes and thereby recruiting a subset of proteins related to DMV formation (Carriles et al., 291 2021).

293 In the present study, TEM morphological analysis coupled to immunogold labeling of SARS-CoV2942 products have demonstrated to be a valuable tool to better understand the antiviral effects, as 295 previously reported for other viruses (García-Serradilla, 2021; Sachse et al., 2019). Remarkably, 296 the plitidepsin-induced complete blockade of the assembly of viral structures detected here by 297 electron microscopy is rather unique. In the presence of non-toxic, high concentrations of other 298 antiviral drugs, SARS-CoV-2 often assembles small amounts of DMVs and viral particles 299 (Izquierdo-Useros, Cerón and Risco, unpublished results). The generated insights warrant new 
300 experiments that aim to better understand the mechanism of plitidepsin-induced antiviral activity.

301 This knowledge will be crucial to identify the mechanism of action for promising compounds that 302 interfere with host factors whose implication in key biological processes can be applied as a pan303 antiviral strategies.

304

305

306

307 
BIBLIOGRAPHY

Angelini, M.M., Akhlaghpour, M., Neuman, B.W., Buchmeier, M.J., 2013. Severe Acute Respiratory Syndrome Coronavirus Nonstructural Proteins 3, 4, and 6 Induce DoubleMembrane Vesicles. mBio 4, e00524-13. https://doi.org/10.1128/mBio.00524-13

Baggen, J., Vanstreels, E., Jansen, S., Daelemans, D., 2021. Cellular host factors for SARS-CoV2 infection. Nat. Microbiol. https://doi.org/10.1038/s41564-021-00958-0

Beigel, J.H., Tomashek, K.M., Dodd, L.E., Mehta, A.K., Zingman, B.S., Kalil, A.C., Hohmann, E., Chu, H.Y., Luetkemeyer, A., Kline, S., 2020. Remdesivir for the Treatment of Covid19 - Final Report. N Engl J Med 14.

Bojkova, D., Klann, K., Koch, B., Widera, M., Krause, D., Ciesek, S., Cinatl, J., Münch, C., 2020. Proteomics of SARS-CoV-2-infected host cells reveals therapy targets. Nature 583, 469-472. https://doi.org/10.1038/s41586-020-2332-7

Carriles, A.A., Mills, A., Muñoz-Alonso, M.-J., Gutiérrez, D., Domínguez, J.M., Hermoso, J.A., Gago, F., 2021. Structural Cues for Understanding eEF1A2 Moonlighting.

ChemBioChem 22, 374-391. https://doi.org/10.1002/cbic.202000516

de Castro Martin, I.F., Fournier, G., Sachse, M., Pizarro-Cerda, J., Risco, C., Naffakh, N., 2017. Influenza virus genome reaches the plasma membrane via a modified endoplasmic reticulum and Rab11-dependent vesicles. Nat. Commun. 8, 1396. https://doi.org/10.1038/s41467-017-01557-6

Dittmayer, C., Meinhardt, J., Radbruch, H., Radke, J., Heppner, B.I., Heppner, F.L., Stenzel, W., Holland, G., Laue, M., 2020. Why misinterpretation of electron micrographs in SARSCoV-2-infected tissue goes viral. The Lancet 396, e64-e65. https://doi.org/10.1016/S0140-6736(20)32079-1

Edmonds, B.T., Bell, A., Wyckoff, J., Condeelis, J., Leyh, T.S., 1998. The Effect of F-actin on the Binding and Hydrolysis of Guanine Nucleotide by Dictyostelium Elongation Factor 1A. J. Biol. Chem. 273, 10288-10295. https://doi.org/10.1074/jbc.273.17.10288

Eymieux, S., Rouillé, Y., Terrier, O., Seron, K., Blanchard, E., Rosa-Calatrava, M., Dubuisson, J., Belouzard, S., Roingeard, P., 2021a. Ultrastructural modifications induced by SARSCoV-2 in Vero cells: a kinetic analysis of viral factory formation, viral particle morphogenesis and virion release. Cell. Mol. Life Sci. 78, 3565-3576. https://doi.org/10.1007/s00018-020-03745-y

Eymieux, S., Uzbekov, R., Rouillé, Y., Blanchard, E., Hourioux, C., Dubuisson, J., Belouzard, S., Roingeard, P., 2021b. Secretory Vesicles Are the Principal Means of SARS-CoV-2 Egress. Cells 10, 2047. https://doi.org/10.3390/cells10082047

García-Serradilla, M., 2021. Light and electron microscopy imaging unveils new aspects of the antiviral capacity of silver nanoparticles in bunyavirus-infected cells. Virus Res. 16.

Garibaldi, B.T., Wang, K., Robinson, M.L., Zeger, S.L., Bandeen-Roche, K., Wang, M.-C., Alexander, G.C., Gupta, A., Bollinger, R., Xu, Y., 2021. Comparison of Time to Clinical Improvement With vs Without Remdesivir Treatment in Hospitalized Patients With COVID-19. JAMA Netw. Open 4, e213071. https://doi.org/10.1001/jamanetworkopen.2021.3071

Gordon, D.E., Jang, G.M., Bouhaddou, M., Xu, J., Obernier, K., White, K.M., O'Meara, M.J., Rezelj, V.V., Guo, J.Z., Swaney, D.L., Tummino, T.A., Hüttenhain, R., Kaake, R.M., Richards, A.L., Tutuncuoglu, B., Foussard, H., Batra, J., Haas, K., Modak, M., Kim, M., Haas, P., Polacco, B.J., Braberg, H., Fabius, J.M., Eckhardt, M., Soucheray, M., Bennett, M.J., Cakir, M., McGregor, M.J., Li, Q., Meyer, B., Roesch, F., Vallet, T., Mac Kain, A., 
Miorin, L., Moreno, E., Naing, Z.Z.C., Zhou, Y., Peng, S., Shi, Y., Zhang, Z., Shen, W., Kirby, I.T., Melnyk, J.E., Chorba, J.S., Lou, K., Dai, S.A., Barrio-Hernandez, I., Memon, D., Hernandez-Armenta, C., Lyu, J., Mathy, C.J.P., Perica, T., Pilla, K.B., Ganesan, S.J., Saltzberg, D.J., Rakesh, R., Liu, X., Rosenthal, S.B., Calviello, L., Venkataramanan, S., Liboy-Lugo, J., Lin, Y., Huang, X.-P., Liu, Y., Wankowicz, S.A., Bohn, M., Safari, M., Ugur, F.S., Koh, C., Savar, N.S., Tran, Q.D., Shengjuler, D., Fletcher, S.J., O’Neal, M.C., Cai, Y., Chang, J.C.J., Broadhurst, D.J., Klippsten, S., Sharp, P.P., Wenzell, N.A., Kuzuoglu-Ozturk, D., Wang, H.-Y., Trenker, R., Young, J.M., Cavero, D.A., Hiatt, J., Roth, T.L., Rathore, U., Subramanian, A., Noack, J., Hubert, M., Stroud, R.M., Frankel, A.D., Rosenberg, O.S., Verba, K.A., Agard, D.A., Ott, M., Emerman, M., Jura, N., von Zastrow, M., Verdin, E., Ashworth, A., Schwartz, O., d'Enfert, C., Mukherjee, S., Jacobson, M., Malik, H.S., Fujimori, D.G., Ideker, T., Craik, C.S., Floor, S.N., Fraser, J.S., Gross, J.D., Sali, A., Roth, B.L., Ruggero, D., Taunton, J., Kortemme, T., Beltrao, P., Vignuzzi, M., García-Sastre, A., Shokat, K.M., Shoichet, B.K., Krogan, N.J., 2020. A SARS-CoV-2 protein interaction map reveals targets for drug repurposing. Nature 583, 459-468. https://doi.org/10.1038/s41586-020-2286-9

Grein, J., Ohmagari, N., Shin, D., Diaz, G., Asperges, E., Castagna, A., Feldt, T., Green, G., Green, M.L., Lescure, F.-X., Nicastri, E., Oda, R., Yo, K., Quiros-Roldan, E., Studemeister, A., Redinski, J., Ahmed, S., Bernett, J., Chelliah, D., Chen, D., Chihara, S., Cohen, S.H., Cunningham, J., D’Arminio Monforte, A., Ismail, S., Kato, H., Lapadula, G., L’Her, E., Maeno, T., Majumder, S., Massari, M., Mora-Rillo, M., Mutoh, Y., Nguyen, D., Verweij, E., Zoufaly, A., Osinusi, A.O., DeZure, A., Zhao, Y., Zhong, L., Chokkalingam, A., Elboudwarej, E., Telep, L., Timbs, L., Henne, I., Sellers, S., Cao, H., Tan, S.K., Winterbourne, L., Desai, P., Mera, R., Gaggar, A., Myers, R.P., Brainard, D.M., Childs, R., Flanigan, T., 2020. Compassionate Use of Remdesivir for Patients with Severe Covid-19. N. Engl. J. Med. NEJMoa2007016. https://doi.org/10.1056/NEJMoa2007016

Hotokezaka, Y., Többen, U., Hotokezaka, H., van Leyen, K., Beatrix, B., Smith, D.H., Nakamura, T., Wiedmann, M., 2002. Interaction of the Eukaryotic Elongation Factor 1A with Newly Synthesized Polypeptides. J. Biol. Chem. 277, 18545-18551. https://doi.org/10.1074/jbc.M201022200

Imran, Mohd., Kumar Arora, M., Asdaq, S.M.B., Khan, S.A., Alaqel, S.I., Alshammari, M.K., Alshehri, M.M., Alshrari, A.S., Mateq Ali, A., Al-shammeri, A.M., Alhazmi, B.D., Harshan, A.A., Alam, Md.T., Abida, A., 2021. Discovery, Development, and Patent Trends on Molnupiravir: A Prospective Oral Treatment for COVID-19. Molecules 26, 5795. https://doi.org/10.3390/molecules26195795

Losada, A., Muñoz-Alonso, M.J., García, C., Sánchez-Murcia, P.A., Martínez-Leal, J.F., Domínguez, J.M., Lillo, M.P., Gago, F., Galmarini, C.M., 2016. Translation Elongation Factor eEF1A2 is a Novel Anticancer Target for the Marine Natural Product Plitidepsin. Sci. Rep. 6, 35100. https://doi.org/10.1038/srep35100

Mateyak, M.K., Kinzy, T.G., 2010. eEF1A: Thinking Outside the Ribosome. J. Biol. Chem. 285, 21209-21213. https://doi.org/10.1074/jbc.R110.113795

Miller, S.E., Goldsmith, C.S., 2020. Caution in Identifying Coronaviruses by Electron Microscopy. J. Am. Soc. Nephrol. 31, 2223-2224. https://doi.org/10.1681/ASN.2020050755

Ogando, N.S., Dalebout, T.J., Zevenhoven-Dobbe, J.C., Limpens, R.W.A.L., van der Meer, Y., Caly, L., Druce, J., de Vries, J.J.C., Kikkert, M., Bárcena, M., Sidorov, I., Snijder, E.J., 2020. SARS-coronavirus-2 replication in Vero E6 cells: replication kinetics, rapid 
403

404

405

406

407

408

409

410

411

412

413

414

415

416

417

418

419

420

421

422

423

424

425

426

427

428

429

430

431

432

433

434

435

436

437

438

439

440

441

442

443

444

adaptation and cytopathology. J. Gen. Virol. 101, 925-940.

https://doi.org/10.1099/jgv.0.001453

Oudshoorn, D., Rijs, K., Limpens, R.W.A.L., Groen, K., Koster, A.J., Snijder, E.J., Kikkert, M., Bárcena, M., 2017. Expression and Cleavage of Middle East Respiratory Syndrome Coronavirus nsp3-4 Polyprotein Induce the Formation of Double-Membrane Vesicles That Mimic Those Associated with Coronaviral RNA Replication. mBio 8, mBio.0165817, e01658-17. https://doi.org/10.1128/mBio.01658-17

Rodon, J., Muñoz-Basagoiti, J., Perez-Zsolt, D., Noguera-Julian, M., Paredes, R., Mateu, L., Quiñones, C., Perez, C., Erkizia, I., Blanco, I., Valencia, A., Guallar, V., Carrillo, J., Blanco, J., Segalés, J., Clotet, B., Vergara-Alert, J., Izquierdo-Useros, N., 2021. Identification of Plitidepsin as Potent Inhibitor of SARS-CoV-2-Induced Cytopathic Effect After a Drug Repurposing Screen. Front. Pharmacol. 12, 646676. https://doi.org/10.3389/fphar.2021.646676

Sachse, M., Fernández de Castro, I., Tenorio, R., Risco, C., 2019. The viral replication organelles within cells studied by electron microscopy, in: Advances in Virus Research. Elsevier, pp. 1-33. https://doi.org/10.1016/bs.aivir.2019.07.005

Sun, Y., Du, C., Wang, B., Zhang, Y., Liu, X., Ren, G., 2014. Up-regulation of eEF1A2 promotes proliferation and inhibits apoptosis in prostate cancer. Biochem. Biophys. Res. Commun. 450, 1-6. https://doi.org/10.1016/j.bbrc.2014.05.045

Tenorio, R., de Castro, I.F., Knowlton, J.J., Zamora, P.F., Lee, C.H., Mainou, B.A., Dermody, T.S., Risco, C., 2018. Reovirus NS and NS Proteins Remodel the Endoplasmic Reticulum to Build Replication Neo-Organelles. mBio 9, 15.

van den Worm, S.H.E., Knoops, K., Zevenhoven-Dobbe, J.C., Beugeling, C., van der Meer, Y., Mommaas, A.M., Snijder, E.J., 2011. Development and RNA-Synthesizing Activity of Coronavirus Replication Structures in the Absence of Protein Synthesis. J. Virol. 85, 5669-5673. https://doi.org/10.1128/JVI.00403-11

White, K.M., Rosales, R., Yildiz, S., Kehrer, T., Miorin, L., Moreno, E., Jangra, S., Uccellini, M.B., Rathnasinghe, R., Coughlan, L., Martinez-Romero, C., Batra, J., Rojc, A., Bouhaddou, M., Fabius, J.M., Obernier, K., Dejosez, M., Guillén, M.J., Losada, A., Avilés, P., Schotsaert, M., Zwaka, T., Vignuzzi, M., Shokat, K.M., Krogan, N.J., GarcíaSastre, A., 2021. Plitidepsin has potent preclinical efficacy against SARS-CoV-2 by targeting the host protein eEF1A. Science 371, 926-931. https://doi.org/10.1126/science.abf4058

Wolff, G., Melia, C.E., Snijder, E.J., Bárcena, M., 2020a. Double-Membrane Vesicles as Platforms for Viral Replication. Trends Microbiol. 28, 1022-1033. https://doi.org/10.1016/j.tim.2020.05.009

Wolff, G., Zheng, S., Koster, A.J., Snijder, E.J., Bárcena, M., 2020b. A molecular pore spans the double membrane of the coronavirus replication organelle. Science 5.

Zhang, X., Shi, H., Chen, J., Shi, D., Li, C., Feng, L., 2014. EF1A interacting with nucleocapsid protein of transmissible gastroenteritis coronavirus and plays a role in virus replication. Vet. Microbiol. 172, 443-448. https://doi.org/10.1016/j.vetmic.2014.05.034 


\section{FINANCIAL SUPPORT}

446 This research was funded by Pharma Mar, which commercializes Aplidin/Plitidepsin. The authors

447 also acknowledge the crowdfunding initiative \#Yomecorono (https://www.yomecorono.com).

448 N.I-U. is supported by grant PID2020-117145RB-I00 from the Spanish Ministry of Science and 449 Innovation. C.R. is supported by grant RTI2018-094445-B-I00 (MCI/AEI/FEDER, UE) from the 450 Spanish Ministry of Science and Innovation.

451

\section{ACKNOWLEDGEMENTS}

453 We acknowledge J. Pedroza from the CMCiB for his constant help at the BSL3 facility.

454

\section{COMPETING INTEREST}

456 P.A., J.V-A and N.I-U. are inventors in a patent application related to Aplidin/Plitidepsin 457 (EP20382821.5). Unrelated to the submitted work, N.I-U. reports institutional grants from Grifols, 458 Dentaid, Hipra and Palobiofarma. The authors declare that no other competing financial interests 459 exist.

461 DATA AVAILABILITY. Data related to this work is available from corresponding authors upon 462 reasonable request. 
Figure 1: Transmission electron microscopy of Vero E6 cells infected with SARS-CoV-2 and effects of plitidepsin. (A) to (C) ultrathin sections of normally infected cells at an MOI of 0.02 and $48 \mathrm{~h}$ post-inoculation. (A) Cell containing a viral replication organelle made of a collection of double-membrane vesicles (DMVs) near the nucleus $(\mathrm{N})$. Numerous viral particles are seen on the cell surface (arrows and inset in A). (B) DMVs have a round shape and fibrillar content. (C) Individual intracellular viral particles (arrows) are seen inside single-membrane vesicles. Large group of viruses inside a vacuole (V). Budding of viral particles in RER membranes (arrowhead and inset). (D) to (F) Ultrathin sections of Vero E6 cells infected with SARS-CoV-2 and treated with $0.2 \mu \mathrm{M}$ plitidepsin. Low (D) and high (E and F) magnification views show that these cells contain lipid droplets (LD), large glycogen deposits (GD) and an altered Golgi complex (G) but no viral structures. M, mitochondrion. Scale bars, $1 \mu \mathrm{m}$ in A and D; $200 \mathrm{~nm}$ in B, C, E and F.

Figure 2: Transmission electron microscopy of Vero E6 cells infected with SARS-CoV-2 in the absence or presence of two doses of plitidepsin. (A) to (C) Normally infected cells. Low (A) and high (B and C) magnification of ultrathin sections of cells infected $48 \mathrm{~h}$ at an MOI of 0.02 (A) Groups of characteristic double membrane vesicles (DMVs; asterisks) occupy large areas of infected cells. (B) Typical DMVs exhibit electron dense membranes and sometimes a fibrillar content. (C) Single membrane vesicles with viruses (arrows) are often found in the close vicinity of DMVs. (D) to (F) Low (D) and high (E) and (F) magnification of Vero E6 cells infected with SARS-CoV-2 $48 \mathrm{~h}$ at an MOI of 0.02 and treated with $0.05 \mu \mathrm{M}$ plitidepsin. Cells contain lipid droplets (arrows in D), swollen Golgi stacks (G), mitochondria with swollen cristae (M) and swollen endoplasmic reticulum (ER) cisternae. No viral structures are seen. (G) to (I) Cells infected with SARS-CoV-2 $48 \mathrm{~h}$ at an MOI of 0.02 and treated with $0.2 \mu \mathrm{M}$ plitidepsin. Cells contain lipid droplets (arrows in G), glycogen deposits (GD in H and I), swollen ER and altered mitochondria (I). N, nucleus; P, plasma membrane. Scale bars, $1 \mu \mathrm{m}$ in A, D and G; $200 \mathrm{~nm}$ in B, C, E, F, H and I. 
496 Figure 3: Immunogold detection of SARS-CoV-2 nucleocapsid protein in infected cells in the

497 absence or presence of two doses of plitidepsin. Ultrathin sections of cells were incubated with 498 anti-N primary antibody followed by a secondary antibody conjugated with $10 \mathrm{~nm}$ colloidal gold 499 particles and visualized by TEM. (A) to (C) Ultrathin sections of cells infected for $48 \mathrm{~h}$ with SARS-

$500 \mathrm{CoV}-2$ at an MOI of 0.02. (A) Low magnification image of an infected cell with characteristic 501 DMVs (asterisks) near the nucleus (N). (B) High magnification image of a group of intracellular 502 viruses (arrowheads) inside a vacuole (V). Viral particles and areas of cytosol are labelled. (C) 503 Labelled extracellular virions (arrows) on the cell surface. (D) to (F) Cells infected 48h with 504 SARS-CoV-2 at an MOI of 0.02 and treated with $0.05 \mu \mathrm{M}$ plitidepsin. Low (D) and high (E) and 505 (F) magnification images of cells show no labeling. P, plasma membrane. (G) to (I) Cells infected $50648 \mathrm{~h}$ with SARS-CoV-2 at an MOI of 0.02 and treated with $0.2 \mu \mathrm{M}$ plitidepsin. Low $(\mathrm{G})$ and high $507(\mathrm{H})$ and (I) magnification images of cells show no labeling. Scale bars, Scale bars, $0.5 \mu \mathrm{m}$ in A, D 508 and $\mathrm{G} ; 200 \mathrm{~nm}$ in $\mathrm{B}, \mathrm{C}, \mathrm{E}, \mathrm{F}, \mathrm{H}$ and I.

512 Figure 4. Immunogold labelling of SARS-CoV-2 dsRNA in infected cells in the absence or 513 presence of two doses of plitidepsin. Ultrathin sections of cells were incubated with anti-dsRNA 514 primary antibody followed by a secondary antibody conjugated with $10 \mathrm{~nm}$ colloidal gold particles 515 and visualized by TEM, (A) to (C) Ultrathin sections of cells infected $48 \mathrm{~h}$ with SARS-CoV-2 at 516 an MOI of 0.02. (A) Low magnification image of an infected cell with characteristic DMVs 517 (asterisk) near the nucleus (N). (B) and (C) High magnification images of labelled DMVs 518 (arrowheads). (D) to (F) Cells infected $48 \mathrm{~h}$ with SARS-CoV-2 at an MOI of 0.02 and treated with $5190.05 \mu \mathrm{M}$ plitidepsin. Low (D) and high (E) and (F) magnification images of cells show no labeling. 520 (G) to (I) Cells infected $48 \mathrm{~h}$ with SARS-CoV-2 at an MOI of 0.02 and treated with $0.2 \mu \mathrm{M}$ 521 plitidepsin. Low $(\mathrm{G})$ and high $(\mathrm{H})$ and $(\mathrm{I})$ magnification images of cells show no labeling. Scale 522 bars, Scale bars, $1 \mu \mathrm{m}$ in A, D and G; $200 \mathrm{~nm}$ in B, C, E, F, H and I. 


\section{Supplementary Materials}

530 Supplementary Figure 1. Effects of plitidepsin in the morphology of mock-infected Vero E6

531 cells. (A) and (B) Low and high magnification images of control Vero E6 cells with normal nucleus

532 (N), Golgi complex (G) and mitochondria (M). (C) and (D) Low and high magnification images,

533 respectively, of Vero E6 cells treated $48 \mathrm{~h}$ with $0.2 \mu \mathrm{M}$ plitidepsin. Cells show lipid droplets (LD),

534 altered mitochondria (M), glycogen deposits (GD) and swollen Golgi (G). Scale bars, $500 \mathrm{~nm}$.

536 Supplementary Figure 2. Dose-dependent effects of plitidepsin in mock-infected Vero E6 cells. (A) to (C) control cells. Low (A) and high (B) and (D) magnification images, respectively, of untreated cells. (D) to (F) Vero E6 cells incubated $48 \mathrm{~h}$ with $0.05 \mu \mathrm{M}$ plitidepsin. Low (D) and high (E) and (F) magnification images, respectively. Arrows in (D) point to lipid droplets. (G) to (I) Vero E6 cells incubated $48 \mathrm{~h}$ with $0.2 \mu \mathrm{M}$ plitidepsin. Low (G) and high (H) and (I) magnification images, respectively. N, nucleus; P, plasma membrane; G, Golgi complex; ER, 542 endoplasmic reticulum; LB, lamellar body; GD, glycogen deposits; LD, lipid droplet. Scale bars, $5431 \mu \mathrm{m}$ in A, D and G; $200 \mathrm{~nm}$ in B, C, E, F, H and I.

545 Supplementary Figure 3. Immunogold cytochemical control of anti-nucleocapsid (N) antibody in non-infected Vero E6 cells, with and without plitidepsin. Ultrathin sections of cells were

547 incubated with anti-N primary antibody followed by a secondary antibody conjugated with $10 \mathrm{~nm}$ 548 colloidal gold particles and visualized by TEM. (A) to (C) control, non-infected Vero E6 cells in the absence of plitidepsin. Low (A) and high (B) and (C) maginification images. (D) to (F) Vero E6 cells treated $48 \mathrm{~h}$ with $0.05 \mu \mathrm{M}$ plitidepsin. Low (D) and high (E) and (F) magnification images. (G) to (I) Vero E6 cells treated $48 \mathrm{~h}$ with $0.2 \mu \mathrm{M}$ plitidepsin. Low (G) and high (H) and (I) magnification images. Cells present no unspecific background. N, nucleus; P, plasma membrane; M, mitochondrion; LB, lamellar body. Scale bars, $0.5 \mu \mathrm{m}$ in A, D and G; $200 \mathrm{~nm}$ in B, C, E, F, H 554 and I.

Supplementary Figure 4. Immunogold cytochemical control of anti-dsRNA antibody in non-

557 infected Vero E6 cells, with and without plitidepsin. Ultrathin sections of cells were incubated 558 with anti-dsRNA primary antibody followed by a secondary antibody conjugated with $10 \mathrm{~nm}$ colloidal gold particles and visualized by TEM. Low (A) and high (B) and (C) magnification 
560 images. (D) to (F) Vero E6 cells treated $48 \mathrm{~h}$ with $0.05 \mu \mathrm{M}$ plitidepsin. Low (D) and high (E) and 561 (F) magnification images. (G) to (I) Vero E6 cells treated $48 \mathrm{~h}$ with $0.2 \mu \mathrm{M}$ plitidepsin. Low (G) 562 and high (H) and (I) magnification images. Cells present no unspecific background. N, nucleus; $\mathrm{P}$, 563 plasma membrane; M, mitochondrion. Scale bars, $1 \mu \mathrm{m}$ in A, D and G; $200 \mathrm{~nm}$ in B, C, E, F, H 564 and I. 

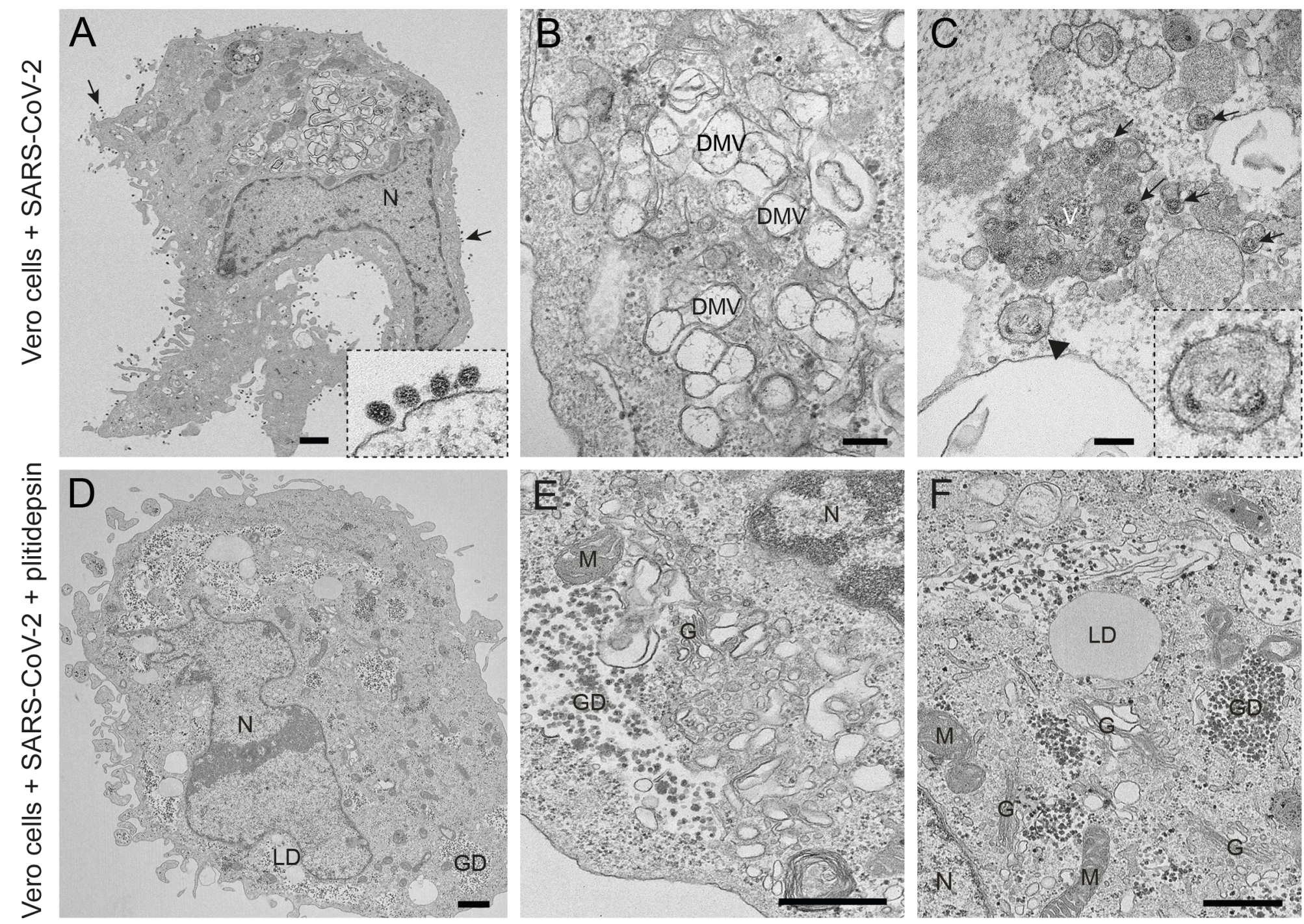


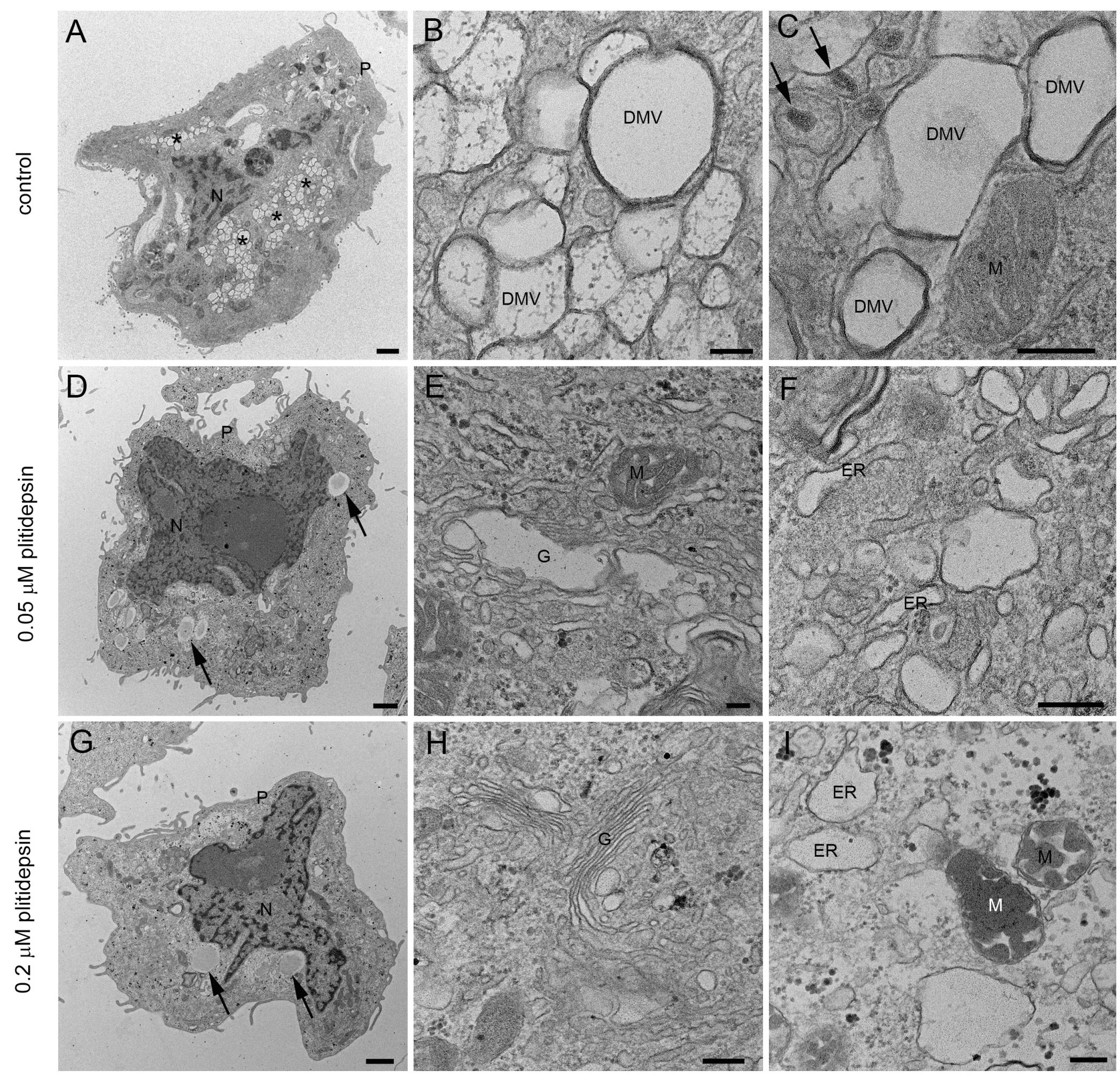


bioRxiv preprint doi: https://doi.org/10.1101/2021.12.16.472880; this version posted December 20, 2021. The copyright holder for this preprint (which was not certified by peer review) is the author/funder, who has granted bioRxiv a license to display the preprint in perpetuity. It is made available under aCC-BY-NC-ND 4.0 International license.
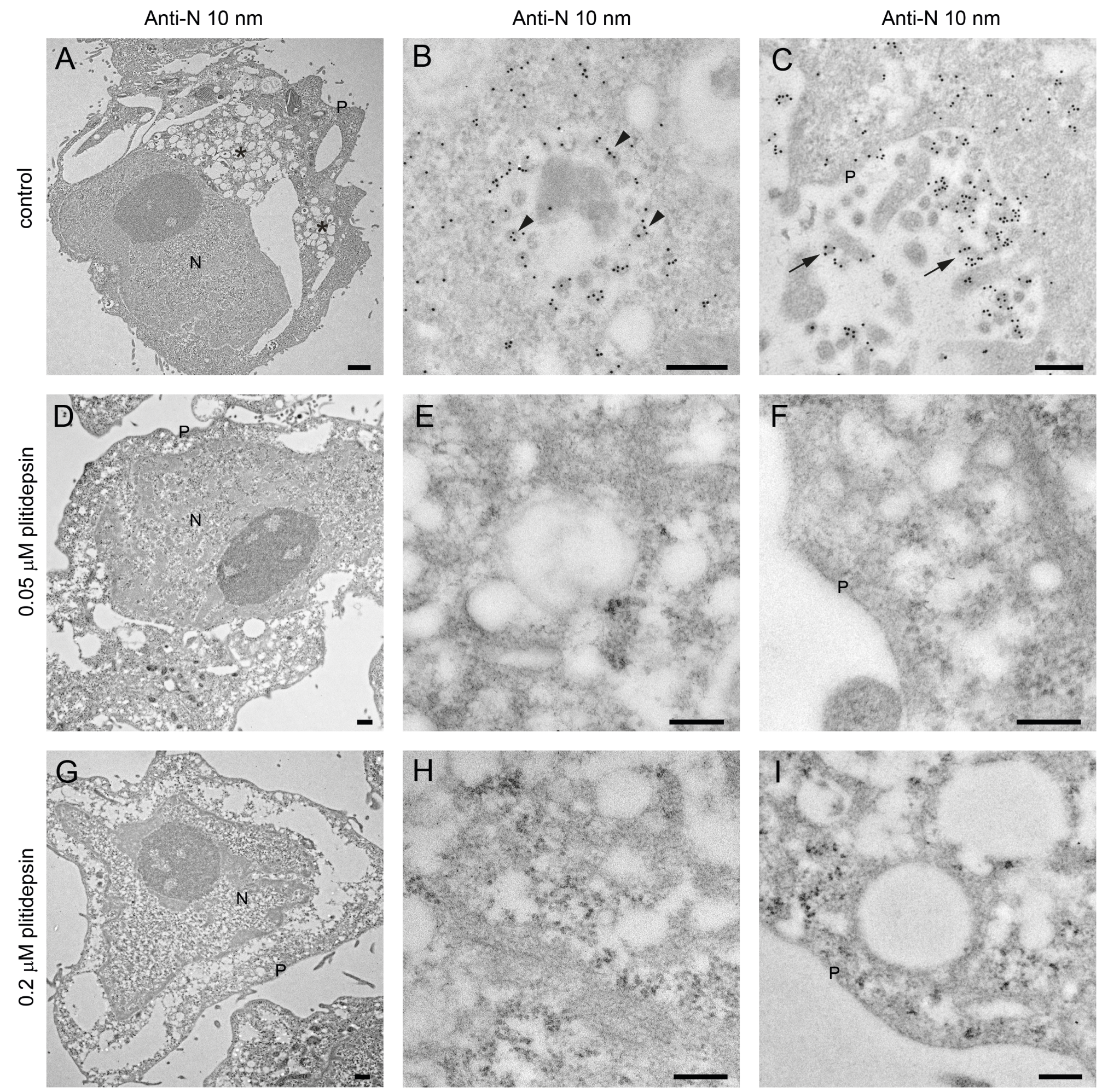
bioRxiv preprint doi: https://doi.org/10.1101/2021.12.16.472880; this version posted December 20, 2021. The copyright holder for this preprint (which was not certified by peer review) is the author/funder, who has granted bioRxiv a license to display the preprint in perpetuity. It is made available under aCC-BY-NC-ND 4.0 International license.
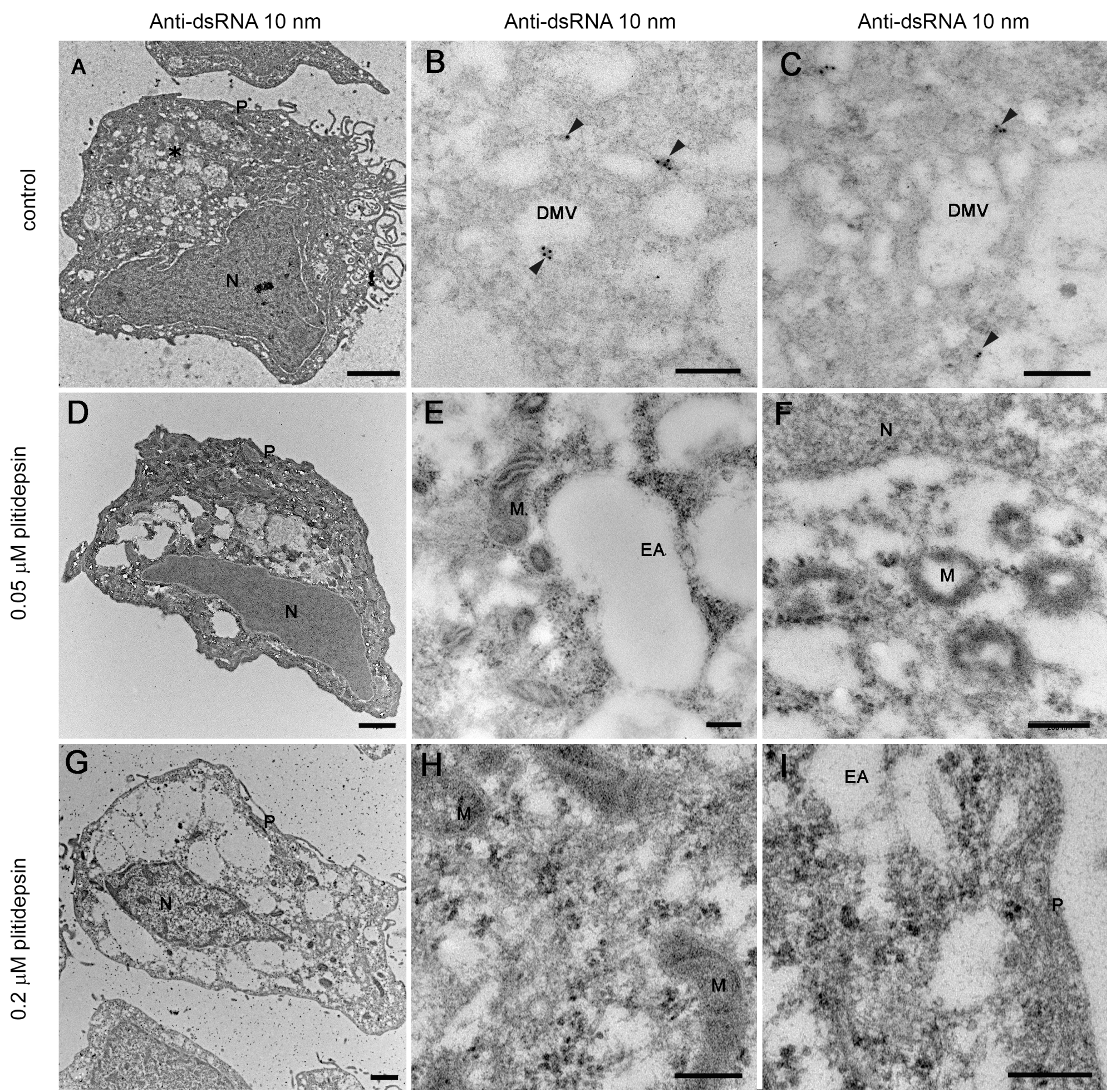